\title{
Solubility and Solvation Parameters of Calcium Carbonate in Mixed Ethanol-water Mixtures at 301.15 K
}

\author{
Esam A. Gomaa
}

Chemistry Department, Faculty of Science, Mansoura University, Mansoura, 35516, Egypt

\begin{abstract}
The molar solubility of calcium carbonate (CC) in mixed ethanol (ETOH)-water solvents was measured at $301.15 \mathrm{~K}$. From the molar solubilities, the solvation parameters, activity coefficients, solubility products, free energies of solvation and transfer free energies for interaction of (CC) from water as reference solvent to mixed $\left(\mathrm{EtOH}-\mathrm{H}_{2} \mathrm{O}\right)$ solvents were evaluated. All the salvation parameters were discussed.
\end{abstract}

Keywords Molar Solubility, Calcium Carbonate, Free Energies of Solvation, Water, Ethanol

\section{Introduction}

The solubility of solutes in mixed solvents is of great practical importance since many industrial process as well as laboratory procedures call for the use of solvent mixtures. The solubility of solutes in mixed solvents depends primarily on the solvation of solutes or their constituent ions by the components of solvent mixtures[1]. Studying the thermodynamics of different salts, is important for evaluating the single ion thermodynamic parameters which help in explain the preferential solvation of the ions[2].

Removal of heavy elements and sulphate ions from an alkaline medium using solvent extraction was very important to get rid of these hard ions[3].

\section{Experimental}

The used calcium carbonate (CC) and ethanol (EtOH) were supplied from Merck Co. The saturated solution of calcium carbonate (CC) was prepared by dissolving little solid amount in closed test tubes containing different EtOH- $\mathrm{H}_{2} \mathrm{O}$ mixtures. The mixtures were then saturated with nitrogen gas as inert atmosphere. The tubes were placed in a shaking thermostat (Model GEL) for a period of one week till equilibrium reached.

The solubility of $\mathrm{CC}$ in each mixture were measured conductmetrically exactly (three times minimum) by using conductmeter of the type YSI model-35 and it was connected with an ultra-thermostat of the type Kottermann-4130. All conductance were measured at $301.15 \mathrm{~K}$. The accuracy of the solubility data is in average of third number after

* Corresponding author:

esam1947@yahoo.com (Esam A. Gomaa)

Published online at http://journal.sapub.org/scit

Copyright (C) 2012 Scientific \& Academic Publishing. All Rights Reserved coma, as in previous work[4].

\section{Results and Discussion}

The molar solubility for calcium carbonate (CC) at 301.15 $\mathrm{K}$ were measured conductmetrically and the $-\log \mathrm{S}$ values are cited in Table 1, in water, ethanol $(\mathrm{EtOH})$ and their mixtures. The solubility of (CC) in water agreed well with that in literature[5].

The activity coefficients were calculated by the use of Debye-Hückel equation[6].

$$
\log \gamma \pm=-0.5062 x(\mathrm{~S})^{0.5}
$$

Where $\mathrm{S}$ is the molar solubility. Their data were tabulated also in Table 1 . The solubility product was calculated by the use of equation 2[2].

$$
\mathrm{pK}_{\mathrm{sp}}=[-2 \log \mathrm{S}+2(\log \gamma \pm)]
$$

Table 1. Molar solubilities (S), activity coefficient ( $\gamma \pm$ ), solubility products $\left(\mathrm{pk}_{\mathrm{sp}}\right)$ and salvation free energies $\left(\Delta G, \Delta G_{t}\right)$ for molar solubilities, and free energies $\mathrm{CaCO}_{3}(\mathrm{CC})$ in different ethanol-water mixtures at $301.15 \mathrm{~K}$

\begin{tabular}{|c|c|c|c|c|c|}
\hline $\begin{array}{c}\text { Xs (mole } \\
\text { fraction) } \\
\text { ethanol }\end{array}$ & $-\log \mathrm{S}$ & $\log \gamma \pm$ & $\mathrm{pK}_{\mathrm{sp}}$ & $\begin{array}{c}\Delta G \\
\mathrm{k} \mathrm{J} / \mathrm{mole}\end{array}$ & $\begin{array}{c}\Delta G_{t} \mathrm{k} \\
\mathrm{J} / \mathrm{mole}\end{array}$ \\
\hline 0 & 4.2097 & -0.00347 & 8.4116 & 48.5026 & 0 \\
\hline 0.031 & 4.3519 & -0.00337 & 8.69706 & 50.1486 & 1.6460 \\
\hline 0.072 & 4.4087 & -0.00316 & 8.81073 & 50.8044 & 2.3018 \\
\hline 0.110 & 4.5648 & -0.00236 & 9.1243 & 52.6121 & 4.1095 \\
\hline 0.171 & 4.6594 & -0.00196 & 9.3141 & 53.7066 & 5.2040 \\
\hline 0.231 & 4.8249 & -0.00156 & 9.6459 & 55.6198 & 7.1172 \\
\hline 0.310 & 5.0236 & -0.00113 & 10.0441 & 57.9159 & 9.41330 \\
\hline 0.553 & 5.2980 & -0.00075 & 10.5937 & 61.0849 & 12.5823 \\
\hline 0.735 & 5.6528 & -0.00055 & 11.3042 & 65.1818 & 16.6792 \\
\hline 1.0 & 6.1495 & -0.00042 & 12.29908 & 70.9185 & 22.4158 \\
\hline
\end{tabular}

Where $\mathrm{S}$ is the molar solubility of (CC) in mixed EtOH- $\mathrm{H}_{2} \mathrm{O}$ solvents. $\mathrm{pK}_{\mathrm{sp}}$ data are given in Table 1. From these solubility products the Gibbs free energies of solvation 
and the transfer Gibbs free energies from water to mixed solvents were calculated by using the following equations[4] and[5]. Their values are tabulated also in Table (1).

$$
\begin{gathered}
\Delta G=2.303 R T p K_{s p} \\
\Delta G_{t}=\Delta G_{S}-\Delta G_{W}
\end{gathered}
$$

It was concluded that the Gibbs free energies of transfer $\Delta G_{t}$ increase in positivity by increasing the mole fraction of ethanol in the mixtures. This is due to more difficult solvation in the mixed solvents than that of water. Polar solvents like $\mathrm{H}_{2} \mathrm{O}$ or EtOH or their mixtures cannot penetrate (CC) lattice due to the very high heats of formation, free energy, entropy and heat capacity for (CC) salts[7], calcite and aragonite.

Table 2. Molar thermodynamic properties of pure (CC) solid

\begin{tabular}{|c|c|c|c|c|}
\hline & $\Delta \mathrm{H}_{\mathrm{f}}^{\circ}$ & $\Delta \mathrm{G}_{\mathrm{f}}^{\circ}$ & $\mathrm{S}^{\circ}$ & $\mathrm{Cp}^{\circ}$ \\
\hline & $\mathrm{k} . \mathrm{J} / \mathrm{mol}$ & $\mathrm{k} \mathrm{J} / \mathrm{mol}$ & $\mathrm{J} / \mathrm{K} . \mathrm{mol}$ & $\mathrm{J} / \mathrm{K} . \mathrm{mol}$ \\
\hline $\mathrm{CaCO}_{3}$ (calcite) & -1206.92 & -1128.79 & 92.9 & 81.88 \\
\hline $\mathrm{CaCO}_{3}$ (aragonite) & -1207.13 & -1127.75 & 88.7 & 81.25 \\
\hline
\end{tabular}

Ethanol is much less polar than water. Since $(\mathrm{CC})$ is insoluble in water. Therefore (CC) would be even less soluble in ethanol.

According to this small solubility, applying some thermodynamic model was done to explain the precipitation of some insoluble salts[8].

Table 3. Molar (VM), van der (VW) and electrostriction volumes (Ve) for (CC) in mixed EtOH- $\mathrm{H}_{2} \mathrm{O}$ solvents at $301.15 \mathrm{~K}$ (in $\mathrm{cm} 3 / \mathrm{mol}$ )

\begin{tabular}{|c|c|c|c|}
\hline $\mathrm{X}_{\mathrm{s}}(\mathrm{EtOH})$ & $\mathrm{V}_{\mathrm{M}}$ & $\mathrm{V}_{\mathrm{W}}$ & $\mathrm{V}_{\mathrm{e}}$ \\
\hline 0 & 100.089 & 66.158 & -33.931 \\
\hline 0.03 & 107.864 & 71.298 & -36.566 \\
\hline 0.07 & 111.0174 & 73.383 & -37.634 \\
\hline 0.11 & 111.452 & 73.669 & -37.783 \\
\hline 0.17 & 111.561 & 73.742 & -37.818 \\
\hline 0.231 & 111.800 & 73.899 & -37.901 \\
\hline 0.310 & 112.107 & 74.1027 & -38.004 \\
\hline 0.553 & 120.825 & 79.865 & -40.960 \\
\hline 0.735 & 121.999 & 80.641 & -41.358 \\
\hline 1.0 & 140.571 & 92.917 & -47.674 \\
\hline
\end{tabular}

The molar volumes $\left(\mathrm{V}_{\mathrm{M}}\right)$ for $(\mathrm{CC})$ in mixed EtOH- $\mathrm{H}_{2} \mathrm{O}$ were calculated by dividing the molecular weight by the exact solution densities and their values are tabulated in Table (3). The packing density (P) as explained by Kim (in ref. 6), i.e., the relation between Van der Waals volume $\left(V_{w}\right)$ and the molar volume $\left(\mathrm{V}_{\mathrm{M}}\right)$ for relatively large molecules was found to be constant and equal 0.661 .

$$
P=\frac{V_{W}}{V_{M}}=0.661 \pm 0.017
$$

The electrostriction volumes $\left(\mathrm{V}_{\mathrm{e}}\right)$ which is the volume compressed by the solvent can be calculated by using equation (6) as follows:

$$
V_{e}=\left(V_{W}-V_{M}\right)
$$

All the different volumes for (CC) in mixed EtOH- $\mathrm{H}_{2} \mathrm{O}$ solvents were represented in Table (3). The data in Table (3) indicate that the volumes increase by more adding alcohol favoring more energy required for salvation, i.e., less salvation process.

\section{REFERENCES}

[1] Yizhak Marcus, "Solubility and solvation in mixed solvent systems", Pure and Applied Chem., 62 (1990) 2069-2076

[2] Esam A. Gomaa, "Single ion free energies of some ion and the hydrophobic interactions of $\mathrm{Ph}_{4} \mathrm{AsBPh}_{4}$ and $\mathrm{Ph}_{4} \mathrm{SbB} \mathrm{Ph}_{4}$ in mixed ethanol-water solvents". Thermochimica Acta, 156 (1989) 91-99

[3] Cleophase Ngoie Mpinga, "Removal of aluminium and sulphate ions from alkaline medium using solvent extraction"., Master of Technology, Faculty of Engineering, Cape Peninsula University of Technology (2009)

[4] E. A. Gomaa, "Solvation parameters of lead acetate in mixed water-N, N-Dimethylformamide mixtures at $298.15 \mathrm{~K}$ ". Analele Universitätii den Bucuresti, 19, 1 (2010) 45-48

[5] Perry's "Chemical Engineering Handbook, Section 2, Physical and Chemical data, $8^{\text {th }}$ Edition, McGraw Hill., USA (2008)

[6] A. A. El-Khouly, Esam A. Gomaa and S Abou El-Leef, "Conductometry and solubility study of $\mathrm{Cd}^{2+}$ Kryptofix-221 complexes in various hydroorganic solvents", Bulletin of Electrochemistry, 19(4), (2003) 153-164

[7] Jim Plambec la @ Malberta. Ca

[8] L. Vicum, M. Hazzotti and J. Baldyga, "Applying a thermodynamic model to the non-stoichiometric precipitation of barium sulphate". Chemical Engineering and Technology, 26(2003) 352-333 